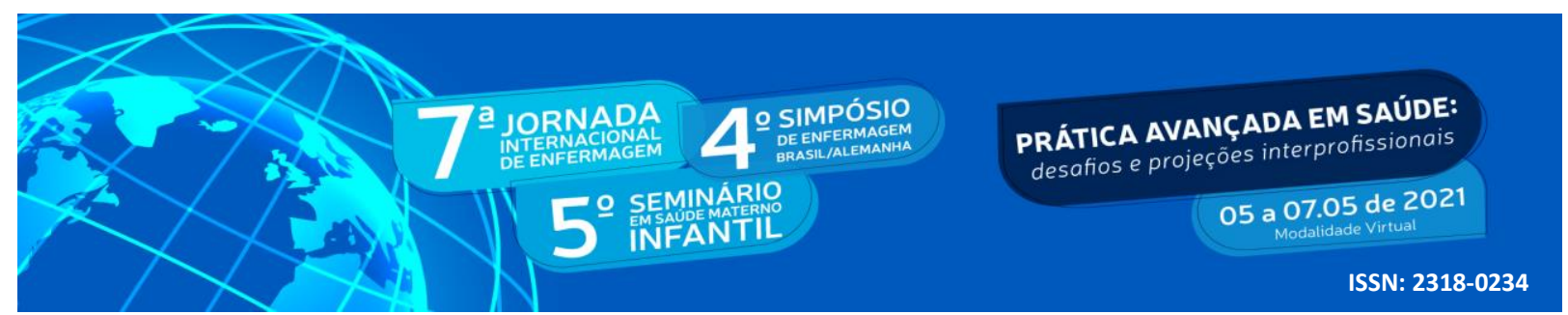

\title{
DESENVOLVIMENTO INFANTIL: UM OLHAR SOBRE CRIANÇAS QUE FREQUENTAM UMA CRECHE
}

\author{
Maria Paula Ramalho Barbosa ${ }^{1}$; Patrício de Almeida Costa ${ }^{2}$; Barbara de Souza \\ Ferreira ${ }^{3}$; Layla Caroline Lino da Silva ${ }^{4}$; Cayane Maria da Silva Santos ${ }^{5}$; Nathanielly \\ Cristina Carvalho de Brito Santos ${ }^{6}$
}

\section{RESUMO}

O desenvolvimento consiste em habilidades linguísticas, motoras, cognitivas e psicossociais, que promovem o aumento da competência e autonomia da criança. É a fase em que a criança melhor responde aos estímulos do ambiente, devido à plasticidade cerebral, justificando a importância do acompanhamento da saúde da criança. O objetivo geral do estudo foi avaliar o desenvolvimento de crianças que frequentam uma creche municipal no Curimataú Paraibano. Trata-se de um estudo transversal, quantitativo, realizado no período de março a abril de 2017, com 51 crianças com idade entre 0 e 36 meses, matriculadas na instituição e com caderneta. Ao analisar os aspectos da vigilância do desenvolvimento, constatou-se que $52,94 \%$ das crianças foram classificadas com "Alerta para o desenvolvimento infantil", 31,37\% "Desenvolvimento adequado" e 15,69\% "Provável atraso no desenvolvimento". Faz-se necessário refletir sobre a qualidade da atenção ofertada à criança e capacidade de detectar precocemente alterações para uma intervenção oportuna.

Palavras-chave: Creche; Desenvolvimento infantil; Saúde

\begin{abstract}
The development consists of linguistic, motor, cognitive and psychosocial skills, which promote the increase of the child's competence and autonomy. Phase in which the child responds better to the stimuli of the environment, due to his brain plasticity, justifying the importance of monitoring the child's health. The general objective of the study was to evaluate the development of children who attend a municipal day care center in the city of Cuité / PB. This is a descriptive, cross-sectional and quantitative study, carried out from March to April 2017, with 51 children aged between 0 and 36 months, enrolled at the institution and with a booklet. When analyzing the data observed, the phenotypic changes and developmental milestones for age, of the 51 children evaluated, $50.98 \%$ were classified as "Adequate development with risk factor", 31.37\% "Adequate development", 15, 69\% "Probable delay in development" and "1.96\%"Alert for child development". It is important to reflect on the quality of care provided to children.
\end{abstract}

Key Words: Nursery; Child development; Health.

1 Graduanda em Enfermagem pela Universidade Federal de Campina Grande - Campus Cuité. E-mail: ramalhobarbosa61@gmail.com

${ }^{2}$ Graduando em Enfermagem pela Universidade Federal de Campina Grande - Campus Cuité. E-mail: patricioalmeida13@hotmail.com

${ }^{3}$ Enfermeira pela Universidade Federal de Campina Grande - Campus Cuité. E-mail:barbara.souzaf@ hotmail.com ${ }^{4}$ Graduanda em Enfermagem pela Universidade Federal de Campina Grande - Campus Cuité. E-mail: layla.carol.lino.s2@hotmail.com

5 Graduanda em Enfermagem pela Universidade Federal de Campina Grande - Campus Cuité. E-mail: cayanemaria3@gmail.com

${ }^{6}$ Orientadora. Doutora em Enfermagem pela Universidade Federal da Paraíba (UFPB). E-mail: $\underline{\text { nathanielly.cristina@professor.ufcg.edu.br }}$ 


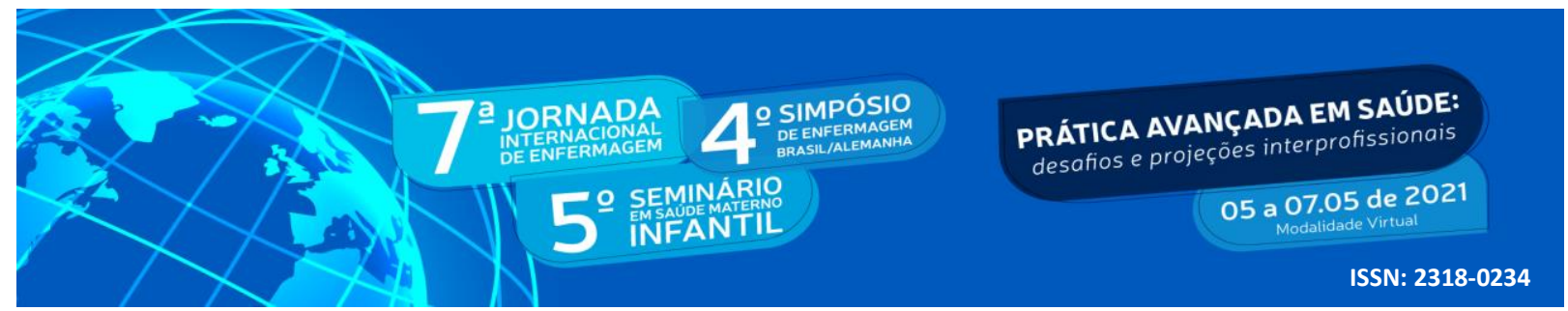

\section{INTRODUÇÃ̃O}

O desenvolvimento infantil pode ser definido como um processo multidimensional e integral, que se inicia com a concepção e que engloba o crescimento físico, a maturação neurológica, o desenvolvimento comportamental, sensorial, cognitivo e de linguagem, assim como as relações socioafetivas. Tem como efeito tornar a criança capaz de responder às suas necessidades e as do seu meio, considerando seu contexto de vida (PANCIERA; CARDOSO; JUDIR, 2017).

Portanto, o pré-natal e os anos iniciais da infância (primeira infância) são fases decisivas no processo de desenvolvimento, visto que o mesmo é constituído pela interação das características biopsicológicas, herdadas geneticamente, e experiências oferecidas pelo meio ambiente, condições indispensáveis no processo de seguimento da criança para o alcance do seu potencial (VERISSIMO; SOUZA, 2015).

Durante esse período são definidas as principais características do jeito de ser da criança e a maneira como ela irá interagir com as pessoas na sua família, na escola e em outros espaços da sua comunidade. Sendo assim, cada criança tem a sua própria forma de explorar o mundo, de construir seus conhecimentos a partir da comunicação com as pessoas próximas e com o ambiente em que elas vivem (VERISSIMO; SOUZA, 2015).

Em se tratando de crianças com alguma condição que afeta o desenvolvimento, no Brasil, considerando a primeira infância os dados superam os 13.806 .733 milhões de crianças com algum tipo de deficiência, pois este número se refere apenas aos menores de cinco anos identificados no último censo realizado pelo Instituto Brasileiro de Geografia e Estatística (IBGE) no ano de 2010. (BRASIL, 2010)

Quando o comprometimento no desenvolvimento infantil é por deficiência intelectual, a microcefalia se destaca como a condição mais responsável, com 2.865 novos casos confirmado no Brasil entre 2015 e 2018, diante da Síndrome congênita do Zika vírus, sendo a maior concentração no Nordeste, com 1.883 casos, e o estado da Paraíba entre os cinco com maior número de casos, com percentual de 6,9\% do total de casos notificados (BRASIL, 2019).

Dessa forma, faz-se necessário entender sobre o desenvolvimento infantil, o funcionamento do Sistema Nervoso Central e de outras dimensões do funcionamento orgânico, bem como a qualidade dos estímulos e das relações que a criança vivencia, tendo em vista os 


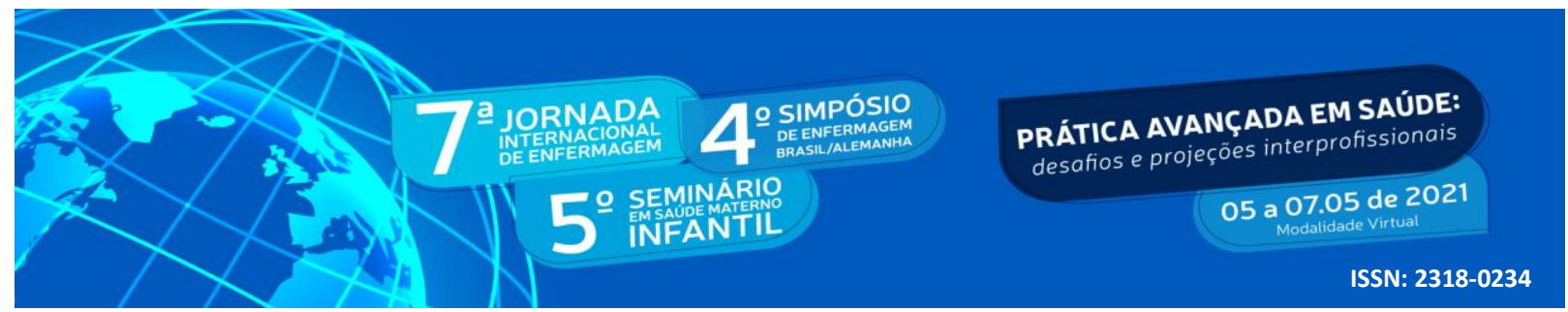

aspectos biológicos, relacionais, contextuais e culturais (PANCIERA; CARDOSO; JUDIR, 2017).

Sendo assim, a creche é vista como um espaço que pode potencializar o desenvolvimento da criança, visto que, é um ambiente formal de educação e serve como apoio às necessidades básicas das crianças e cumprindo também uma função assistencial, já que os pais ou responsáveis necessitam deixá-las num local seguro durante o seu período laboral. Nesse sentido, a entrada da criança na creche, hoje, não visa apenas resolver as necessidades da família, mas sim, envolver a criança em um processo educativo para o seu desenvolvimento infantil (RODRIGUEZ; FREIRE, 2017).

Para promover a vigilância do desenvolvimento infantil, a Caderneta da Criança, destinada a todos os recém-nascidos e distribuída gratuitamente para família é o instrumento referência para o registro do acompanhamento, além de guia para a promoção da saúde, e prevenção de agravos, no entanto, exige um preenchimento correto pelos profissionais (OLIVINDO; SOUSA; SILVA, 2020).

Ante o exposto, visto a importância da identificação de possíveis alterações no desenvolvimento infantil, se faz necessário à implementação da vigilância do desenvolvimento em crianças, a fim de se intervir precocemente diante de uma classificação de alerta para o desenvolvimento ou provável atraso, a partir das condutas de estimulação preconizadas pelo Ministério da Saúde.

Logo, a proposição de uma investigação que avalie o desenvolvimento de crianças que frequentam creches municipais, identificando possíveis alterações para a faixa etária, poderá contribuir para que elas cresçam de forma saudável e expondo seu potencial, possibilitando também intervenções em saúde de forma precoce quando necessário.

\section{OBJETIVO}

Avaliar o desenvolvimento de crianças de 0 a 3 anos que frequentam uma creche municipal.

\section{METODOLOGIA}

Trata-se de um estudo descritivo, transversal e de abordagem qualitativa, como parte de uma pesquisa maior intitulada "DESENVOLVIMENTO INFANTIL: UM OLHAR SOBRE CRIANÇAS QUE FREQUENTAM UMA CRECHE”, realizada em seis creches municipais no 


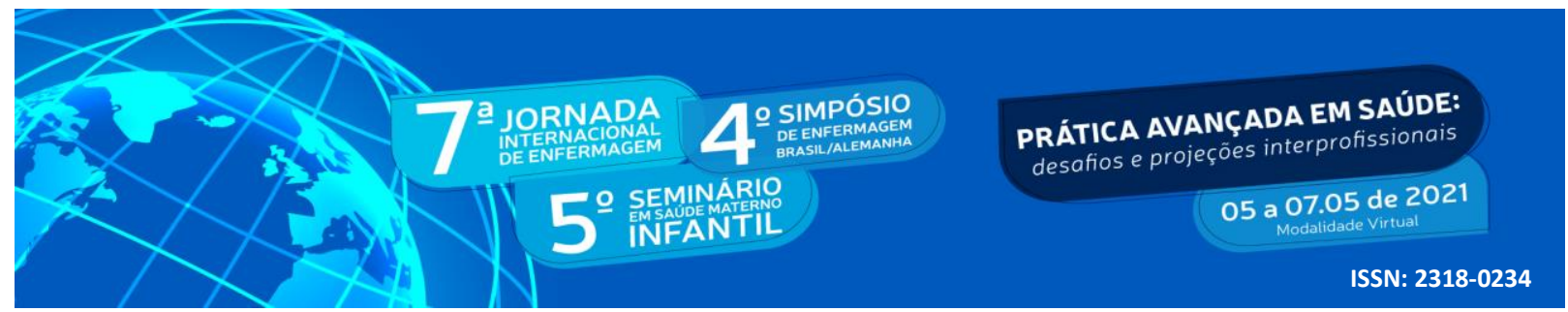

Curimataú Paraibano (três rurais e três urbanas) as quais ofertam serviços de cuidado direto à criança, bem como de educação voltados para faixa etária de 0 a menor de 5 anos.

A população foi constituída de 120 crianças, que frequentavam as creches durante o período da coleta de dados. E a amostra foi composta de 51 crianças que atenderam aos critérios de inclusão e exclusão. A coleta de dados foi realizada entre os meses de fevereiro e abril de 2017, por meio de um instrumento sócio demográfico e de informações de saúde da criança, e outro de vigilância do desenvolvimento infantil, preconizado pelo Ministério da Saúde, para avaliação dos marcos do desenvolvimento infantil, que foi a caderneta da criança.

Os dados foram digitados em dupla entrada, com checagem das planilhas para validação do processo, armazenados através do programa Excel versão 7.0 da Microsoft $^{\circledR}$. Os resultados foram analisados de forma descritiva, apresentados por meio de tabelas e gráficos e discutidos com base na literatura pertinente.

Todos os procedimentos realizados nesta pesquisa foram designados a partir da Resolução $\mathrm{n}^{\circ}$ 466/2012 do Conselho Nacional de Saúde (CNS), que preconiza a regulamentação ética em pesquisas envolvendo seres humanos no Brasil (BRASIL, 2012). Além disso, o estudo foi realizado somente após aprovação do projeto pelo Comitê de Ética em Pesquisa do Hospital Universitário Alcides Carneiro sob parecer $n^{\circ} 1.912 .728$ e Certificado de Apresentação para Apreciação Ética (CAAE) 63319416.9.0000.5182.

\section{RESULTADOS E DISCUSSÃO}

Os primeiros anos de vida são definitivos para criança, pois o intenso desenvolvimento cerebral a torna mais suscetível às influências positivas ou negativas, de suas experiências (PEREIRA., 2015). Diante disso, emerge a importância do acompanhamento e atenção dos profissionais de saúde e familiares, tendo como meta, a detecção precoce de possíveis alterações e uma intervenção oportuna que possa minimizar as repercussões para o desenvolvimento (OLIVINDO; SOUSA; SILVA, 2020).

Fizeram parte deste estudo 51 crianças com idades entre 0 e 36 meses, sendo a maioria do sexo masculino $(56,86 \%)$ e maiores de 12 meses $(80,39 \%)$. A tabela 1 apresenta as condições socioeconômicas e demográficas das crianças. Foram destaques mães com anos de estudos entre 8 a 12 anos (60,78\%); casadas ou que vivem em uma união estável (72,55\%); com renda familiar de até 1 salário mínimo (72,55\%). Em relação ao domicílio, todas residem em casas de 


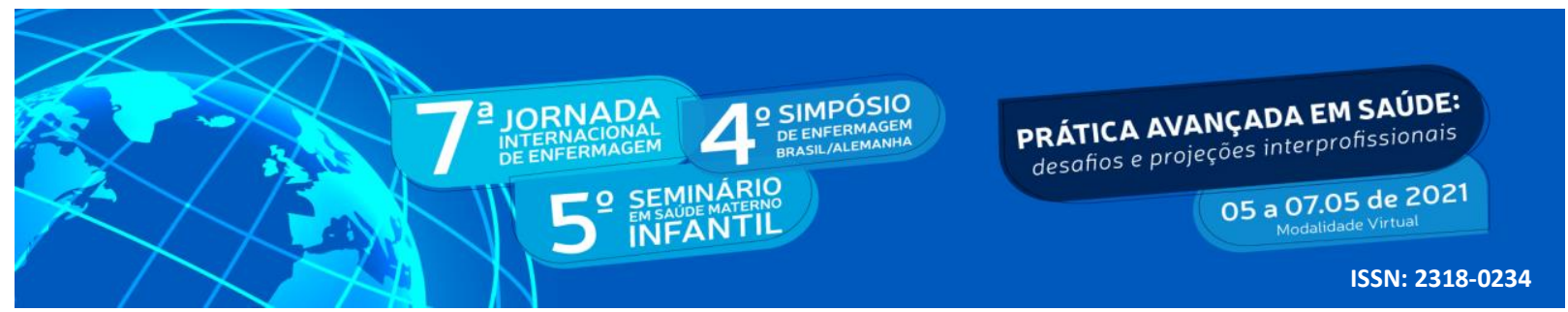

tijolos, 56,86\% possuem água encanada, 50,98\% com rede de esgoto e 96,08\% têm a fossa como destino das fezes, bem como destino do lixo coletado por carro coletor.

No que diz respeito aos fatores ambientais, sociais e biológicos que permeiam o contexto da criança e podem contribuir, ou vir a prejudicar diretamente o desenvolvimento infantil, destaca-se o fato de a maioria das famílias terem apresentado entre os aspectos socioeconômicos renda familiar de até 1 salário mínimo. Concordando com os achados, estudo (PEREIRA et al, 2017) realizado em Goiânia (GO) apresentou relação direta entre a baixa renda familiar e o risco de atraso na linguagem de crianças que frequentam centros institucionais.

Outra característica relevante para o cuidado à saúde e avaliação da criança, são os anos de estudos das mães, que neste estudo foi entre 8 e 12 anos para a maioria das entrevistadas. Estudo (CORSI., 2016) realizado no interior de São Paulo, em centros de estudos municipais e particulares evidenciou que mães com maior escolaridade escolhem creches de maior qualidade para os filhos.

Tabela 1 - Caracterização das condições sócio econômica e demográfica. Cuité, PB, 2017.

\begin{tabular}{lcc}
\hline \multicolumn{1}{c}{ Variável } & $\mathbf{N}$ & $\mathbf{\%}$ \\
\hline Idade da mãe & $\mathbf{5 1}$ & $\mathbf{1 0 0}$ \\
$<19$ & 2 & 3,92 \\
$20-29$ & 31 & 60,78 \\
$30-40$ & 18 & 35,30 \\
Anos de estudo da mãe & & \\
$\leq 8$ & 5 & 9,80 \\
$8-12$ & 31 & 60,78 \\
$\geq 12$ & 15 & 29,41 \\
Estado Civil & & $\mathbf{1 0 0}$ \\
Casada/união estável & 37 & 72,55 \\
Solteira & 10 & 19,61 \\
Viúva & 1 & 1,96 \\
Separada/divorciada & 3 & 5,88 \\
Renda (Salário mínimo) & & $\mathbf{1 0 0}$ \\
0 a 1 & 37 & 72,55 \\
2 a 4 & 13 & 25,49 \\
5 a 7 & 1 & 1,96 \\
Tipo de domicílio & & $\mathbf{1 0 0}$ \\
Madeira & - & - \\
Tijolo & & 100 \\
Taipa & - & - \\
Número de cômodos & & $\mathbf{1 0 0}$ \\
1 - 3 & 2 & 3,92 \\
4- 7 & & 70,58 \\
8- 10 & 36 & 25,50 \\
Número de pessoas & 13 & $\mathbf{1 0 0}$ \\
& &
\end{tabular}




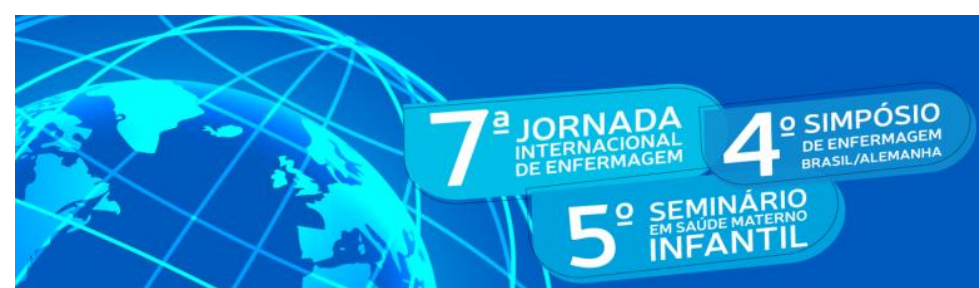

PRÁTICA AVANÇADA EM SAÚDE:

ços interprofissionais

desafios e projeçoes interprofissionais

05 a 07.05 de 2021

ISSN: 2318-0234

1-3

4-6

7-10

Água encanada

Sim

Não

Rede de esgoto

Sim

Não

Destino das fezes

Céu aberto

Rede de esgoto

Fossa

Destino do lixo

Terreno baldio

Rua

Carro coletor

Queima
39,21

49,09

11,70

100

56,86

43,14

100

50,98

49,02

100

1,96

1,96

96,08

100

1,96

1,96

96,08

Fonte: Dados da pesquisa. Cuité-PB, 2017.

A tabela 2 demonstra a exposição das crianças quanto aos fatores de risco abordados na caderneta da criança. Identificou-se que $62,75 \%$ das crianças apresentaram um ou mais fatores de risco para o desenvolvimento neuropsicomotor, com presença de algum problema na gestação, parto e nascimento como pré-eclâmpsia, hipertensão, infecção urinária, hemorragia, descolamento de placenta, anemia e diabetes, e a presença de algum familiar com deficiência ou doença mental $(37,25 \%)$.

É pertinente ressaltar que dentre os fatores de risco para o desenvolvimento infantil, problemas na gestação, parto e nascimento que teve como destaque a hipertensão arterial durante a gestação, apresentada na história de saúde de seis crianças. Segundo o Ministério da Saúde essa é uma problemática comum, que ocorre em cerca de $10 \%$ de todas as gestações, sendo uma das causas de mortalidade (BRASIL, 2012).

Destaca-se a prematuridade, como uma condição que sofre influência de um pré-natal inadequado, e que pode contribuir para problemas no desenvolvimento infantil, como demonstra estudo (FORMIGA et al., 2015) comparativo realizado no hospital materno de Goiânia, onde foram avaliados pré-termos de 0 a 6 meses, com baixo peso ao nascer, e que obteve resultados indicativos de atraso do desenvolvimento em todos os bebês pré-termos avaliados. 


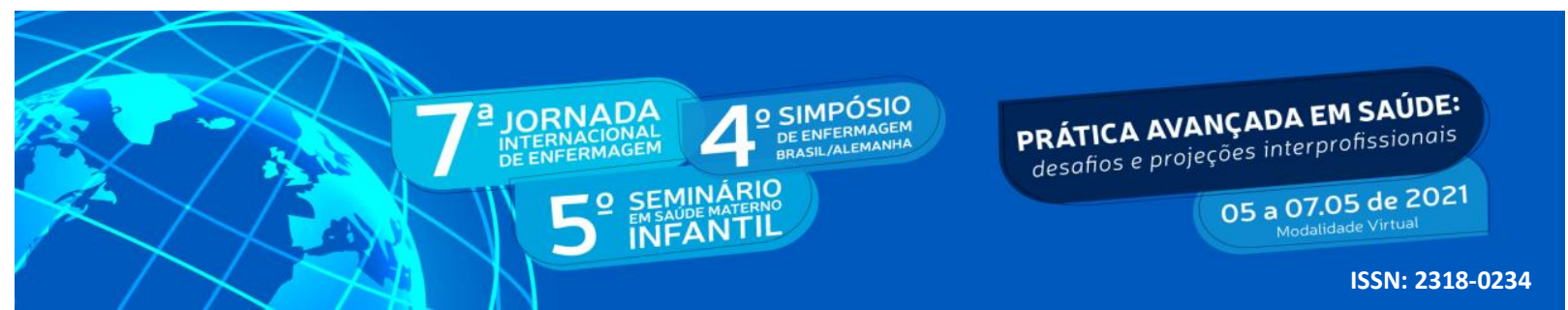

Outro fator de risco identificado no presente estudo foi a presença de algum familiar com deficiência ou doença mental. Estudo (RODRIGUEZ; FREIRE, 2017) demonstrou que no Brasil 23,9\% da população, ou seja, quase um em cada quatro brasileiros tem alguma deficiência. Nos estados do Nordeste, em especial o Rio Grande do Norte e Paraíba, essa prevalência é ainda maior sendo de $(27,7 \%)$ na Paraíba, ocupando o terceiro lugar no ranking nacional, ficando atrás somente do RN e do Ceará. (IBGE, 2010). Além disso, considerando a repercussão dessa condição para o cuidado da criança, foi a depressão materna apresentada por cinco mães durante a gestação.

Tabela 2 - Exposição aos fatores de risco para o desenvolvimento infantil. Cuité, PB, 2017.

\begin{tabular}{lcccccc}
\hline \multicolumn{1}{c}{ Fatores de risco } & \multicolumn{2}{c}{ Sim } & \multicolumn{2}{c}{ Não } & \multicolumn{2}{c}{ TOTAL } \\
\cline { 2 - 7 } & $\mathbf{N}$ & $\mathbf{\%}$ & $\mathbf{N}$ & $\mathbf{\%}$ & $\mathbf{N}$ & \% \\
\hline $\begin{array}{l}\text { Ausência ou pré-natal } \\
\text { incompleto? }\end{array}$ & 2 & 3,92 & 49 & 96,08 & 51 & 100 \\
Problemas na gestação, & 13 & 25,49 & 38 & 74,51 & 51 & 100 \\
parto ou nascimento? & & & & & & \\
Prematuridade & 3 & 5,89 & 48 & 94,11 & 51 & 100 \\
Peso abaixo de 2500 & 3 & 5,89 & 48 & 94,11 & 51 & 100 \\
Icterícia grave & 6 & 11,76 & 45 & 88,24 & 51 & 100 \\
Hospitalização no período & 2 & 3,92 & 49 & 96,08 & 51 & 100 \\
pré natal & & & & & & \\
Doença grave: meningite, & - & - & 51 & 100 & 51 & 100 \\
TC e convulsão & & & & & & \\
Parentesco pais & 4 & 7,84 & 47 & 92,16 & 51 & 100 \\
Caso de deficiência ou & 19 & 37,25 & 32 & 62,75 & 51 & 100 \\
doença mental & & & & & & \\
Violência doméstica & 1 & 1,96 & 50 & 98,04 & 51 & 100 \\
Depressão materna & 5 & 9,80 & 46 & 90,20 & 51 & 100 \\
Drogas ou alcoolismo & 2 & 3,92 & 49 & 96,08 & 51 & 100 \\
Suspeita de abuso sexual & 1 & 1,96 & 50 & 98,04 & 51 & 100 \\
\hline
\end{tabular}

Fonte: Dados da pesquisa. Cuité-PB, 2017.

$\mathrm{Na}$ avaliação do desenvolvimento infantil devem-se considerar também as alterações físicas ou fenotípicas que são características apresentadas na criança, podendo ser indicativo de alguma síndrome, e que são destacadas na própria caderneta como: olhos afastados, implantação baixa das orelhas e prega palmar única (BRASIL, 2020), e que no estudo em tela não foi apresentada por nenhuma criança. No entanto, o perímetro cefálico alterado, ou seja, com medida entre $<-2$ e $>+2$ desvios padrão, foi apresentado por oito das crianças, e que é critério para classificação como provável atraso no desenvolvimento infantil, de acordo com o instrumento de vigilância do desenvolvimento adotado pelo Ministério da Saúde. 


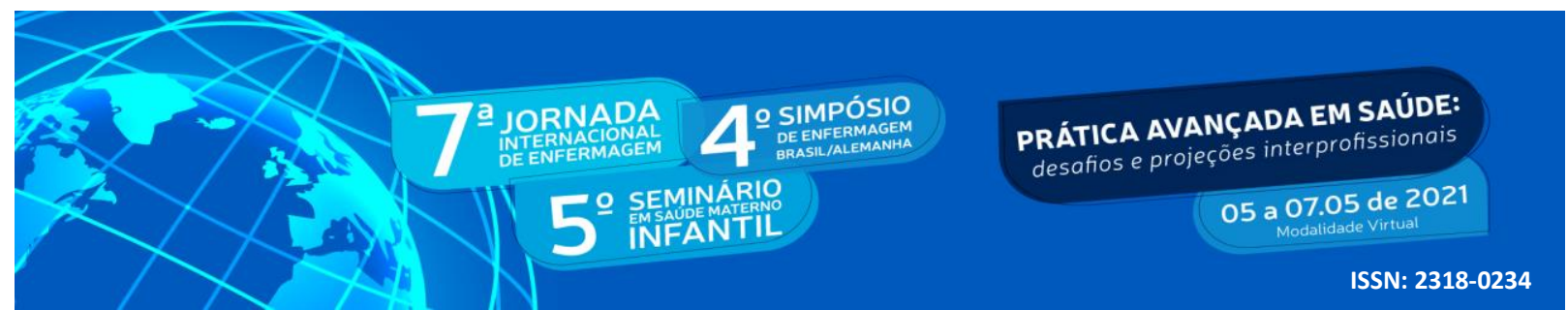

Todas as crianças apresentaram os marcos do desenvolvimento de acordo com a idade, exceto uma criança, no entanto nem todas as crianças que apresentaram os marcos, foram classificadas com "Desenvolvimento adequado", tendo em vista que na avaliação faz-se necessário considerar outros aspectos como: fatores de risco, alterações físicas ou fenotípicas, que direcionam para outras classificações como resultados.

Tabela 3 - Distribuição das crianças em relação às alterações fenotípicas ou físicas. Cuité, PB, 2017.

\begin{tabular}{|c|c|c|c|c|c|c|}
\hline \multirow[t]{2}{*}{ Alterações } & \multicolumn{2}{|c|}{ Sim } & \multicolumn{2}{|c|}{ Não } & \multicolumn{2}{|c|}{ TOTAL } \\
\hline & $\mathrm{N}$ & $\%$ & $\mathrm{~N}$ & $\%$ & $\mathrm{~N}$ & $\%$ \\
\hline $\begin{array}{c}\text { Perímetro cefálico }<- \\
2 \text { escores } \mathrm{z} \text { ou }>+2 \\
\text { escores } \mathrm{z}\end{array}$ & 8 & 15,69 & 43 & 84,31 & 51 & 100 \\
\hline $\begin{array}{l}\text { Alterações } \\
\text { fenotípicas }\end{array}$ & - & - & 51 & 100 & 51 & 100 \\
\hline
\end{tabular}

Fonte: Dados da pesquisa. Cuité-PB, 2017.

Na tabela 4 tem-se a classificação do desenvolvimento infantil considerando os fatores de risco, alterações fenotípicas e os marcos do desenvolvimento. Das 51 crianças avaliadas, constatou-se que 52,94\% das crianças foram classificadas com "Alerta para o desenvolvimento infantil", 31,37\% "Desenvolvimento adequado" e 15,69\% "Provável atraso no desenvolvimento".

Tabela 4 - Classificação das crianças de acordo com a avaliação dos marcos do desenvolvimento infantil. Cuité, PB, 2017.

\begin{tabular}{cc}
\hline Classificações & $\%$ \\
\hline Alerta para o desenvolvimento infantil & $52,94 \%$ \\
Desenvolvimento adequado & $31,37 \%$ \\
Provável atraso no desenvolvimento & $15,69 \%$ \\
\hline
\end{tabular}

Fonte: dados da pesquisa, Cuité - PB 2017.

\section{CONCLUSÃO}

O estudo mostrou que a atenção à saúde da criança inicia-se no pré-natal e tem ação contínua até os 10 anos de idade. Sendo assim, destaca-se a importância da avaliação da criança pelo profissional de saúde considerando os fatores que podem intervir no desenvolvimento saudável e normal. 


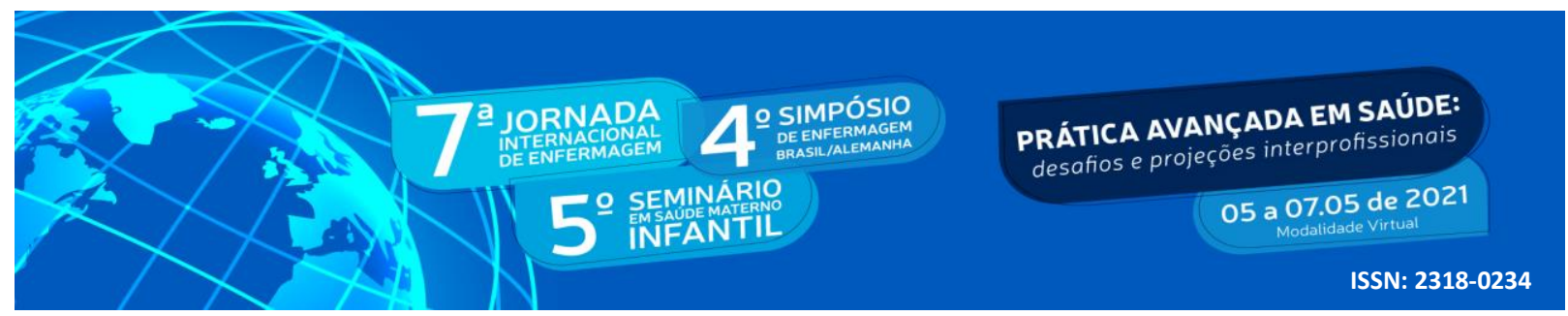

Partindo dessa premissa, a creche é um espaço em que a criança tem oportunidade de se socializar e se desenvolver, de brincar e crescer em conjunto e em interação com seus pares.Para tanto, faz-se necessário a todos os envolvidos no processo de cuidado da criança implementar a vigilância do desenvolvimento com olhar profissional qualificado, e principalmente com serviços estruturalmente adequados para prestação do cuidado integral à criança, família e comunidade

\section{REFERÊNCIAS}

BECKER, S.M.S; PICCININI, C.A. Impacto da creche para a interação mãe-criança. Rev Psc. teor. e Pesq. Brasília. v.35, mar. 2019. Disponível em:< https://www.scielo.br/pdf/ptp/v35/1806-3446-ptp-35-e3532.pdf>. Acesso em: 01 mar. 2021.

BRASIL. Ministério da Saúde, Secretária de Atenção á Saúde. Departamento de Atenção Básica. Diretrizes de estimulação precoce crianças de zero a 3 anos com atraso no desenvolvimento neuropsicomotor. Brasília-DF: MS, 2016. Disponivel em:< http://bvsms.saude.gov.br/bvs/publicacoes/diretrizes_estimulacao_criancas_0a3anos_neuropsi comotor.pdf>. Acesso em: 06 mar. 2021

BRASIL. Ministério da saúde, Secretária de Atenção á Saúde. Departamento de Atenção Básica Caderneta da Criança. Brasília-DF: MS, 2020. Disponível em: http://bvsms.saude.gov.br/bvs/publicacoes/caderneta_crianca_menina_2ed.pdf. Acesso em: 21 mar. 2021

BRASIL. Ministério da saúde, Secretária de Atenção á Saúde. Saúde Brasil: uma análise da situação de saúde e a vigilância da saúde da mulher Brasília-DF: MS, 2012. Disponível em:<http://bvsms.saude.gov.br/bvs/publicacoes/saude_brasil_2011.pdf >. Acesso em: 21 mar. 2021

BRASIL. Ministério da saúde. Boletim Epidemiológico: Monitoramento integrado de alterações no crescimento e desenvolvimento relacionadas à infecção pelo vírus Zika e outras etiologias infecciosas, até a Semana Epidemiológica 52 de 2018. Brasília, v. 50, n.8, 2019. Disponível em: https://www.saude.gov.br/images/pdf/2019/marco/22/2019-001.pdf. Acesso em: 02 mar. 2021.

BRASIL. População residente por tipo de deficiência, segundo a situação do domicílio, o sexo e os grupos de idade. IBGE, Brasilia-DF, 2010. Disponível:

https://sidra.ibge.gov.br/tabela/3425\#resultado. Acesso em: 21 mar. 2021

CORSI, C et al. Repercussões de fatores extrínsecos no desempenho motor fino de crianças frequentadoras de creches. Rev. paul. pediatr. São Paulo, v.34, n.4, Dez. 2016. Disponível em:< https://www.scielo.br/pdf/rpp/v34n4/pt_0103-0582-rpp-34-04-0439.pdf >. Acesso em 18 mar. 2021 


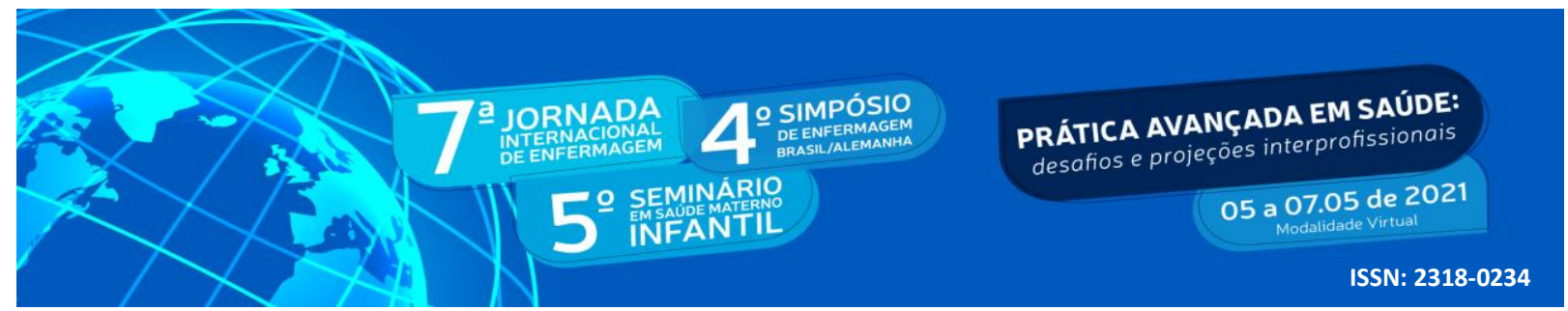

CRESTANI, A.H; MATTANA, F; MORAES, A.B; SOUZA, A.P.R. Fatores socioeconômicos, obstétricos, demográficos e psicossociais como risco ao desenvolvimento infantil. Rev. CEFAC. Santa Maria, v. 15, n.4, p. 847-856, 2017. Disponível em:< https://www.scielo.br/pdf/rcefac/v15n4/12.pdf>. Acesso em: 21 mar. 2021

FORMIGA, C. K. M. R et al. Desenvolvimento motor de bebês pré-termo e a termo de 0 a 6 frequentadoras de creches. Revista Paulista de Pediatria. São Paulo, v. 34, n. 4, p. 439-446, 2016. Disponivel em:< https://www.scielo.br/pdf/rpp/v34n4/pt_0103-0582-rpp-34-040439.pdf $>$. Acesso em: 21. mar. 2021

GAIVA, M.A.M; SILVA, F.B. Caderneta de Saúde da Criança: Revisão Integrativa. Ver. Enferm. UFPE on line. Recife, v. 8, n.3, p.742-9, mar, 2014. Disponível em:< https://periodicos.ufpe.br/revistas/revistaenfermagem/article/viewFile/9733/9830>. Acesso em: 14 mar. 2021

IBGE. INSTITUTO BRASILEIRO DE GEOGRAFIA E ESTATÍSTICA. Pesquisa Nacional por Amostra de Domicílios. Rio de Janeiro:2011 IBGE.

meses de idade. Pediatr. Mod. São Paulo, v. 51, n. 12, 2015. Disponível em:< https://pesquisa.bvsalud.org/portal/resource/pt/lil-783133?lang=en>. Acesso em: 20 mar. 2021

OLIVINDO, D.D.F; SOUZA, J.C.B; SILVA, R.D. Os registros da caderneta de saúde da criança no acompanhamento do crescimento e desenvolvimento infantil. Research, Society and Development. Curitiba, v. 9, n. 10, 2020. Disponível em:< https://rsdjournal.org/index.php/rsd/article/download/9017/8002>. Acesso em: 21 mar. 2021

PANCIERA, S.D.P; CARDOSO, S.C.S; JURDI, A.P.S. Desenvolvimento infantil e o ambiente institucional - experiência com bebês abrigados. Rev. Ciência em extensão. V. 12, n. 1, p. 102-111. 2017. Disponível em:< https://ojs.unesp.br/index.php/revista_proex/article/view/1527/1355>. Acesso em: 21. mar. 2021

PEREIRA, M.M. et al. Prática educativa de enfermeiras na atenção primária à saúde, para o desenvolvimento infantil saudável. Cogitare enferm, v. 20, n. 4, p. 01-07, 2015. Disponível em:< https://revistas.ufpr.br/cogitare/article/view/41649/26746>. Acesso em: 04 mar. 2021

RODRIGUÊS, M.F; FREIRA, R.B. A importância da afetividade na creche. Revista Mosaico. v. 8, n.1, p 11-16, jun., 2017. Disponível em:

http://editora.universidadedevassouras.edu.br/index.php/RM/article/view/924/pdf. Acesso em: 21 mar. 2021

VERISSIMO, M.L.Ô.R; SOUZA, J.M. Desenvolvimento infantil: análise de um novo conceito. Revista Latino Americana de Enfermagem. São Paulo, v.23, n.6, nov. 2015. Disponível em:<https://www.scielo.br/pdf/rlae/v23n6/pt_0104-1169-rlae-23-06-01097.pdf >. Acesso em: 21 mar. 2021 